\title{
The properties and localization of Saprolegnia monoica chitin synthase differ from those of other fungi
}

\author{
Carlos A. Leal-Morales, ${ }^{1}$ Lucien Gay, ${ }^{2}$ Michel Fère ${ }^{2}$ \\ and Salomón Bartnicki-García ${ }^{3}$ \\ Author for correspondence: Salomón Bartnicki-García. Tel: +1 9097874135. Fax: + 19097875113. \\ e-mail: bart@ucrac1.ucr.edu
}

1 Instituto de Investigación en Biología Experimental, Facultad de Quimica, Universidad de

Guanajuato, Guanajuato, México

2 Centre de Génétique Moléculaire et Cellulaire UMR CNRS-5534 Université Lyon I, Villeurbanne, France

3 Department of Plant Pathology, University of California, Riverside, CA 92521, USA
The presence of non-fibrillar $\alpha$-chitin in cellulosic fungi (class Oomycetes) poses intriguing questions as to its role, subcellular localization and evolutionary significance. Previous studies reported on the similarity of chitin synthase from Saprolegnia monoica with that of other fungi. The present work describes important dissimilarities. There was no evidence that the chitin synthase of $\mathbf{S}$. monoica was present in small low-density vesicles (chitosomes). Chitin synthase sedimented with membranous components of high specific gravity (sp. gr. 1.177) that could be partially but distinctly separated from membranes harbouring most of the 1,3- $\beta$-glucan synthase in the cell (sp. gr. 1.158). In contrast to other fungi, the chitin synthase from $S$. monoica was greatly stimulated by digitonin: both membrane-bound and dissociated chitin synthase showed little activity in the absence of digitonin. As in other fungi, the chitin synthase from $S$. monoica was solubilized by digitonin and remained zymogenic after dissociation. However, unlike the enzyme from other fungi, the solubilized chitin synthase of $S$. monoica had a lower sedimentation coefficient, was not stimulated by phospholipids and was not inhibited by high concentrations of digitonin. Unlike the enzyme from Mucor rouxii, the solubilized chitin synthase from $S$. monoica did not bind to a cation exchanger. The enzyme was partially purified by a four-step scheme that included sucrose density-gradient centrifugation, a single passage through a strong anion exchanger and two consecutive passages through a weak anion exchanger. The final preparation contained five to seven polypeptide bands that cochromatographed with the chitin synthase activity, some of which may be part of a presumed chitin synthase macromolecular complex.

Keywords: Saprolegnia monoica, chitin synthase

\section{INTRODUCTION}

Although $\beta$-glucans constitute the main structural polymers in the cell walls of typically cellulosic fungi (class Oomycetes), chitin has been detected in some species as part of the cell wall or in some unique internal structures (cellulin granules) (Lin \& Aronson, 1970; Lee \& Aronson, 1975; Aronson \& Lin, 1978; Campos-Takaki et al., 1982). The occurrence of $\alpha$-chitin in the cell walls of Saprolegnia monoica was proven unequivocally by biochemical and biophysical analyses (Gay et al., 1992;

Abbreviation: MMF, mixed membrane fraction.
Bulone et al., 1992). In hyphal cell walls, chitin appeared as small globular particles though in regenerating protoplasts it had a microfibrillar structure. Enriched preparations of chitin synthase were obtained from cell homogenates of $S$. monoica solubilized with digitonin (Gay et al., 1993). The solubilized enzyme catalysed the synthesis in vitro of spindle-like crystals of chitin. The chitin synthase of $S$. monoica exhibited properties similar to those reported for chitin synthase of other fungi such as zymogenicity, stimulation by $\mathrm{Mg}^{2+}$, apparent $K_{\mathrm{m}}$ for UDP-GlcNAc and inhibition by polyoxin (Ruiz-Herrera et al., 1984; Gay et al., 1989; Gooday, 1990). The specific activity of chitin synthase from $S$. monoica was lower than that observed with 
enzymes from typical chitinous fungi, but higher than those characterized in other Oomycetes: Leptomitus, Apodachlyella or Apodachlya (Huizar \& Aronson, 1986, 1987).

Molecular genetic evidence indicates the presence of several chitin synthase genes $(c h s)$ in fungal cells (Bulawa, 1993). Recent work on S. monoica showed the presence of two chs genes. One of them (chs-2) has been sequenced and shown to have partial homology with the chs genes from higher fungi (Mort-Bontemps et al., 1997). So far, however, no chitin synthase polypeptide(s) of any organism has been unequivocally purified to homogeneity. Moreover, it appears that fungal chitin synthase does not consist of a single polypeptide but a multipeptide complex (Lending et al., 1991). Thus, the smallest units of active chitin synthase ever isolated are the so-called $16 \mathrm{~S}$ complexes (Ruiz-Herrera et al., 1980; Lending et al., 1991). These $16 \mathrm{~S}$ particles were solubilized by digitonin from membrane-bound chitin synthase. All attempts at further dissociating the $16 \mathrm{~S}$ complexes resulted in loss of enzyme activity. When purified to homogeneity by consecutive anion- and cation-exchange HPLC, the $16 \mathrm{~S}$ particles of chitin synthase from Mucor rouxii contained several polypeptide bands, four of which $(21,23,33$ and $39 \mathrm{kDa})$ correlated with the peak of chitin synthase activity. Presumably, these polypeptides form part of a macromolecular complex that synthesizes chitin in $M$. rouxii.

The present work was undertaken to extend the characterization of the enzyme responsible for chitin synthesis in $S$. monoica and to compare its properties with the chitin synthase of typical fungi. The principal objectives were to establish the subcellular localization of the chitin synthase of $S$. monoica, purify the digitoninsoluble enzyme and determine its polypeptide composition.

\section{METHODS}

Strain and cultivation conditions. S. monoica (strain no. 53967; Centraalbureau voor Schimmelcultures, Baarn, The Netherlands) was maintained on potato dextrose agar plates. Full-grown colonies ( $7 \mathrm{~d}$ old $)$ were cut into $4 \mathrm{~mm}$ square plugs. About 40 plugs were inoculated into $100 \mathrm{ml}$ liquid Machlis medium contained in either $15 \mathrm{~cm}$ plastic Petri dishes or in $1000 \mathrm{ml}$ Erlenmeyer flasks. Two versions of this medium were used: the original formulation (Machlis, 1953) and a modified, Machlis 'plus' medium, where the $\mathrm{N}$ source was glutamic acid $\left(10 \mathrm{~g} \mathrm{l}^{-1}\right)$ instead of $\left(\mathrm{NH}_{4}\right) \mathrm{H}_{2} \mathrm{PO}_{4}\left(0.575 \mathrm{~g} \mathrm{l}^{-1}\right)$. The fungus was grown in stationary conditions for $4 \mathrm{~d}$ at $24^{\circ} \mathrm{C}$.

Cell-free-extract preparation. For most experiments, cells were broken with a Virtis 45 blade homogenizer at $4{ }^{\circ} \mathrm{C}$. Mycelium from 10 Petri dishes was collected and manually cleared of agar plugs and excess liquid. The mycelial mass was divided into $10 \mathrm{~g}$ (fresh wt) portions and each resuspended in $50 \mathrm{ml}$ cold extraction buffer $(20 \mathrm{mM}$ Tris $/ \mathrm{HCl}, \mathrm{pH} 7 \cdot 5,0.5 \mathrm{M}$ sorbitol). Each portion was placed in a $250 \mathrm{ml}$ cup of a Virtis 45 homogenizer and subjected to three $30 \mathrm{~s}$ homogenizations at low speed (setting 5). To minimize heating, the cell suspension was allowed to rest for $30 \mathrm{~s}$ between homogenizations. The suspension was centrifuged at $1000 \mathrm{~g}$ for $15 \mathrm{~min}$, the cell-wall residue was discarded and the supernatant labelled 'crude cell homogenate'.

For chitosome isolation, a cell homogenate was prepared by ballistic disruption. The mycelium from two Petri dish cultures was collected on cheese cloth in a Büchner funnel. After draining excess liquid by mild suction, the mycelium was washed twice with extraction buffer. The mycelium $(8 \cdot 2 \mathrm{~g}$ fresh wt) was then frozen in liquid nitrogen, ground in a mortar (without addition of buffer) and mixed with $25 \mathrm{~g}$ glass beads in a Braun homogenizer bottle. The mixture was disrupted for $20 \mathrm{~s}$ with a Braun MSK homogenizer. The slurry was centrifuged for $15 \mathrm{~min}$ at $1000 \mathrm{~g}$ at $4{ }^{\circ} \mathrm{C}$ to remove cell walls and unbroken cells.

Subcellular fractionation by isopycnic density-gradient centrifugation. To ascertain the location of chitin synthase, samples $(3 \mathrm{ml}$ ) of crude cell homogenate (Virtis homogenization) were loaded on a $32 \mathrm{ml}$ sucrose gradient $(15-54 \%, \mathrm{w} / \mathrm{v}$, in $20 \mathrm{mM}$ Tris $/ \mathrm{HCl}, \mathrm{pH} 7 \cdot 5)$ and centrifuged at $75100 \mathrm{~g}\left(R_{\mathrm{av}}\right)$ in a Beckman SW27 rotor for $20 \mathrm{~h}$ at $4{ }^{\circ} \mathrm{C}$. Fractions of $1.5 \mathrm{ml}$ were collected and assayed for chitin synthase, glucan synthase activity and protein content.

Subcellular separation by velocity sedimentation. Crude cell homogenates $(1000 \mathrm{~g}$ supernatant; $3 \mathrm{ml}$ ) were applied to a $34 \mathrm{ml}$ linear sucrose density gradient $(10-60 \%, \mathrm{w} / \mathrm{v})$ in $20 \mathrm{mM}$ Tris/ $\mathrm{HCl}, \mathrm{pH} 7 \cdot 5$, and centrifuged at $75100 \mathrm{~g}\left(R_{\mathrm{av}}\right)$ in a SW-27 rotor for $1 \mathrm{~h}$. The gradients were fractionated in $0.9 \mathrm{ml}$ fractions on a model 185 density gradient fractionator (ISCO), and placed on ice; even-numbered fractions were assayed for chitin synthase.

Preparation of mixed membrane fraction and digitonindissociated chitin synthase. The crude cell homogenate (Virtis) was centrifuged in a Sorvall SS-34 rotor at $35000 \mathrm{~g}$ $\left(R_{\mathrm{av}}\right)$ for $30 \mathrm{~min}$ at $4{ }^{\circ} \mathrm{C}$. The supernatant was discarded and the pellet was labelled 'mixed membrane fraction' (MMF). To test the effect of digitonin, MMF was resuspended in $10 \mathrm{mM}$ Tris $/ \mathrm{HCl}$, pH 7.5, containing $0.5 \mathrm{M}$ sorbitol. To dissociate ('solubilize') chitin synthase, MMF was suspended ( $2.5 \mathrm{ml}$ per $10 \mathrm{~g}$ mycelium fresh $\mathrm{wt})$ in extraction buffer containing, as indicated, 10,20 or $50 \mathrm{mg}$ digitonin $\mathrm{ml}^{-1}$, and incubated at $4^{\circ} \mathrm{C}$ for $30 \mathrm{~min}$. Solubilized mixtures were centrifuged in a $70 \mathrm{Ti}$ Beckman rotor at $90000 \mathrm{~g}\left(R_{\mathrm{av}}\right)$ for $45 \mathrm{~min}$ at $4{ }^{\circ} \mathrm{C}$ to yield a supernatant labelled 'crude digitoninsoluble chitin synthase'. Alternatively, samples of solubilized mixtures $(4 \mathrm{ml}$ ) were layered on top of a $36 \mathrm{ml}$ linear gradient in Beckman Quick-Seal polyallomer tubes. Two types of gradients were used: a $20-75 \%(\mathrm{v} / \mathrm{v})$ glycerol gradient or a $10-65 \%(\mathrm{w} / \mathrm{v})$ sucrose gradient, both in $20 \mathrm{mM}$ Tris $/ \mathrm{HCl}$, $\mathrm{pH} 7 \cdot 5$, containing $0.1 \%(\mathrm{w} / \mathrm{v})$ digitonin. Gradients were centrifuged at $265000 \mathrm{~g}\left(R_{\mathrm{av}}\right)$ for $3.75 \mathrm{~h}$. After centrifugation, the gradients were fractionated in $0.9 \mathrm{ml}$ fractions as described above and assayed for chitin synthase. $A_{260}$ and $A_{280}$ were monitored. The 10-12 most active fractions were pooled, labelled 'gradient-purified soluble chitin synthase', and stored at $-20^{\circ} \mathrm{C}$.

Determination of sedimentation coefficient. The sedimentation coefficient of crude digitonin-soluble chitin synthase was determined by centrifugation in a $33 \mathrm{ml}$ linear $16-34 \%$ $(\mathrm{w} / \mathrm{v})$ sucrose gradient, in $10 \mathrm{mM}$ Tris buffer (pH 7.5) at $75100 \boldsymbol{g}\left(R_{\mathrm{av}}\right)$ for $20 \mathrm{~h}$ in a Beckman SW-27 rotor. Individual sedimentation markers, catalase $(2.5 \mathrm{mg}), \beta$-galactosidase $(100 \mathrm{U})$ and apoferritin $(10 \mathrm{mg})$, were mixed with samples of chitin synthase and sedimented in parallel gradients. The gradients were fractionated in $1.5 \mathrm{ml}$ fractions. $\beta$-Galactosidase and chitin synthase were assayed enzymically; catalase 
and apoferritin were located by their absorbance at $405 \mathrm{~nm}$ and $280 \mathrm{~nm}$, respectively. Sedimentation depths (ml) of standards were plotted against their $S$ values. The sedimentation coefficient of chitin synthase was estimated by linear regression.

Perfusion ion-exchange chromatography. Poros anion and cation exchangers (flow through particle) (PerSeptive Biosystems) were packed in $1.7 \mathrm{ml}$ plastic (PEEK) columns (4.6 mm diameter, $100 \mathrm{~mm}$ long). The columns were operated with a Varian 5000. All elution buffers were freshly prepared, at a concentration of $20 \mathrm{mM}$ in a $20 \%(\mathrm{v} / \mathrm{v})$ glycerol solution with $0.1 \%(\mathrm{w} / \mathrm{v})$ digitonin. The buffers were filtered through a $0.22 \mu \mathrm{m}$ nitrocellulose filter and degassed. For cationexchange chromatography the buffers used were: $\mathrm{pH} 4 \cdot 5$, acetic acid/NaOH; pH 5.5, MES/NaOH; pH 6.5, $\mathrm{NaH}_{2} \mathrm{PO}_{4} /$ $\mathrm{NaOH} ; \mathrm{pH} 7 \cdot 5, \mathrm{HEPES} / \mathrm{NaOH}$; and $\mathrm{pH} 8.5$, Bicine/NaOH. For anion-exchange chromatography: $\mathrm{pH} 4.5, \mathrm{~N}$-methylpiperazine/ $\mathrm{HCl}$; $\mathrm{pH} 5 \cdot 5$, piperazine/ $\mathrm{HCl} ; \mathrm{pH} 6.5$, Bis-Tris/ $\mathrm{HCl} ; \mathrm{pH} 7.5$, and $\mathrm{pH} 8.0$, Tris $/ \mathrm{HCl} ; \mathrm{pH} 8.5$ and 9.0 , diethanolamine $/ \mathrm{HCl} ; \mathrm{pH} 9.5$, piperazine $/ \mathrm{HCl}$; and $\mathrm{pH} 10.0$ and 10.5 , 1,3-diaminopropane/ $\mathrm{HCl}$. $\mathrm{NaCl}$ concentration was measured with a conductivity meter (Bio-Rad). UV absorbance was monitored at $280 \mathrm{~nm}$ with an ISCO model 1840 absorbance monitor. Enzyme samples of $3 \mathrm{ml}$ were applied using a $1 \mathrm{ml}$ loop. When the absorbance value returned to base line $(12 \mathrm{ml})$ the salt gradient was started. Two $\mathrm{ml}$ fractions were collected, placed on ice and assayed for chitin synthase activity.

For cation-exchange chromatography, Poros 20HS, a strong cation exchanger, was used. Before applying the sample, the column was equilibrated with 15 vols elution buffer containing $1 \mathrm{M} \mathrm{NaCl}$ and then washed with 10 vols buffer without salt.

For anion-exchange chromatography, two anion exchangers were tested: Poros 20HQ, a strong anion exchanger, and Poros 20PI, a weak anion exchanger. For greater capacity, we used two $20 \mathrm{HQ}$ columns in tandem; to keep the pressure within optimum limits, the flow rate was decreased to $2 \mathrm{ml}$ $\min ^{-1}$; the $\mathrm{NaCl}$ gradient was modified accordingly to $0-1 \mathrm{M}$ $\mathrm{NaCl}$ in $25 \mathrm{~min}$. For preliminary tests, samples of $3 \mathrm{ml}$ were applied using a $1 \mathrm{ml}$ loop. For preparative runs, the pooled sucrose density gradient fractions from four gradients (total vol. $41 \mathrm{ml}$ ) were applied to two 20PI columns connected in tandem; to compensate for higher back pressure we slowed the flow rate to $4 \mathrm{ml} \mathrm{min}^{-1}$ and the $\mathrm{NaCl}$ gradient was set to $0-0.25 \mathrm{M}$ in $25 \mathrm{~min}$. The sample from the previous step was diluted with 7 vols unbuffered $20 \%$ glycerol containing $0.1 \%$ digitonin and applied to the column.

Chitin and glucan synthase assays. Enzyme samples of $50 \mu \mathrm{l}$ were assayed with $0.5 \mathrm{mM}$ UDP-GlcNAc, $25 \mathrm{nCi}$ UDP$\left[{ }^{14} \mathrm{C}\right]$ GlcNAc $\left(1.25 \mathrm{GBq} \mathrm{mmol}^{-1}\right), 20 \mathrm{mM}$ GlcNAc, $10 \mathrm{mM}$ $\mathrm{MgCl}_{2}$ and $2 \mu \mathrm{g}$ trypsin $\mathrm{ml}^{-1}$ in $20 \mathrm{mM}$ Tris/ $\mathrm{HCl}$ buffer, $\mathrm{pH} 7.5$, in a total volume of $150 \mu \mathrm{l}$. The assay mixture was incubated at $25^{\circ} \mathrm{C}$ for $30 \mathrm{~min}$ and the reaction was stopped with a drop of glacial acetic acid. Membrane-bound glucan synthase $(50 \mu \mathrm{l})$ was assayed with $4 \mathrm{mM}$ cellobiose, $0.3 \mathrm{mM}$ dithiothreitol (DTT), $0.8 \mathrm{mM}$ UDP-Glc and $4 \mathrm{nCi}$ UDP$\left[{ }^{14} \mathrm{C}\right] \mathrm{Glc}\left(9 \cdot 25 \mathrm{GBq} \mathrm{mmol}^{-1}\right)$ in $20 \mathrm{mM}$ PIPES/Tris buffer, $\mathrm{pH} 6.0$, in a total volume of $150 \mu$ l. The reaction mixtures were filtered on $2.5 \mathrm{~cm}$ glass fibre filters (GF/C, Whatman) and washed with $95 \%$ ethanol $/ 1 \mathrm{M}$ acetic acid $(2: 8, \mathrm{v} / \mathrm{v})$. The discs were dried and their radioactivity measured by liquid scintillation spectrometry.

SDSPAGE analysis. Polyacrylamide resolving gels, 10-15\%, $1.5 \mathrm{~mm}$ thick, were used as described by Cline et al. (1981). Samples were treated with sample buffer as described by
Lending et al. (1991). Electrophoresis was performed overnight at a constant current of $10 \mathrm{~mA}$. Gels were fixed in $50 \%$ methanol, washed with at least four changes of methanol and stained with silver as described by Wray et al. (1981). The silver-stained gels were scanned in an HP Scanner (600 d.p.i.) and the digitized image (TIF file) was analysed with the ImagePro plus program (Media Cybernetics). The density profile of each lane was determined and the data exported to an Excel spreadsheet. Band intensity was calculated as the sum of intensity values under each peak.

Miscellaneous methods. The following proteases were tested: Rhizopus niveus acid protease $\left(110 \mathrm{U} \mathrm{ml}^{-1}\right)$ from Toyobo; chymotrypsin (1100 NF $\mathrm{U} \mathrm{mg}^{-1}$ ) and Streptomyces griseus pronase-P (70000 $\mathrm{U} \mathrm{g}^{-1}$ ) from Calbiochem; and trypsin $(9200$ BAEE $\mathrm{U} \mathrm{mg}^{-1}$ ) from Sigma. The following reagents were from Sigma : 1,3-diaminopropane, dithiothreitol, piperazine, MES, Bicine, Tris, PIPES, GlcNAc, UDP-Glc, and UDP-GlcNAc. Cellobiose was purchased from Calbiochem; $N$-methylpiperazine from Aldrich and diethanolamine from Baker. The following phospholipids were bought from Sigma: phosphatidylinositol, P6636; phosphatidylglycerol, P5531; phosphatidylethanolamine, P4264; phosphatidylcholine, P7524; phosphatidylserine, P6641; lysophosphatidylcholine, L4129. Radioactive substrates, UDP- $\left[{ }^{14} \mathrm{C}\right]$ Glc and UDP- $\left[{ }^{14} \mathrm{C}\right] \mathrm{GlcNAc}$ were from ICN.

\section{RESULTS}

\section{Effect of digitonin on enzyme activity}

Only a small amount of chitin synthase (Fig. 1) was detected in samples of MMF assayed in the absence of digitonin. Upon addition of digitonin, chitin synthase activity increased dramatically up to 26-fold. Maximum activity was attained with around $2 \mathrm{mg}$ digitonin $\mathrm{ml}^{-1}$; higher concentrations were not inhibitory.

The effect of digitonin on the activity of solubilized chitin synthase was also determined on enzyme that had been sedimented through a glycerol density gradient to remove the digitonin used for solubilization (Fig. 2). Samples from the gradient were assayed in the presence or absence of $1 \mathrm{mg}$ digitonin $\mathrm{ml}^{-1}$ (optimum concentration for dissociated chitin synthase). Without digi-

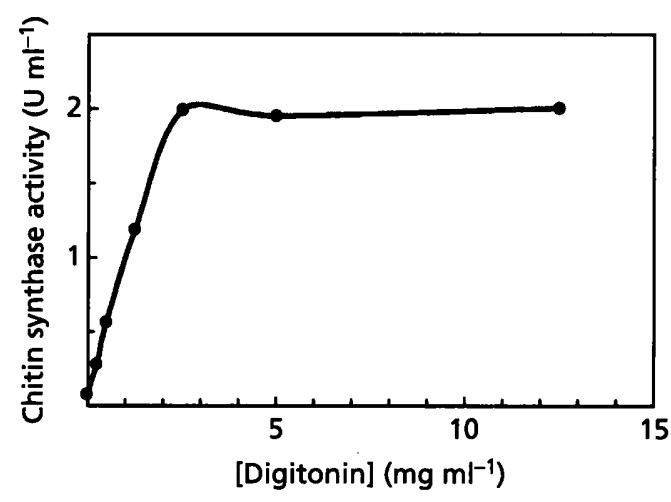

Fig. 1. Effect of digitonin on membrane-bound chitin synthase activity. Samples of MMF were assayed in the presence of different amounts of digitonin (0-12.5 $\mathrm{mg} \mathrm{ml}^{-1}$ final concn). 


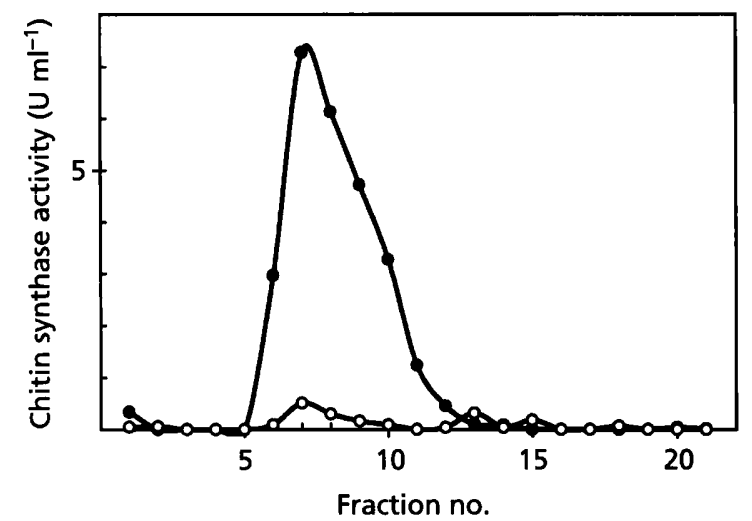

Fig. 2. Effect of digitonin on dissociated chitin synthase. Samples $(2 \mathrm{ml})$ of digitonin-solubilized chitin synthase (MMF extracted with $10 \mathrm{mg}$ digitonin $\mathrm{ml}^{-1}$ ) were centrifuged on a $32 \mathrm{ml}$ linear glycerol gradient $(5-21 \%, v / v)$ for $13 \mathrm{~h}$ at $75100 \mathrm{~g}$ $\left(R_{\mathrm{av}}\right)$ in an SW-27 rotor to remove digitonin. The chitin synthase activity of each fraction was determined in the presence $(O)$ or absence $(O)$ of $1 \mathrm{mg}$ digitonin $\mathrm{ml}^{-1}$.

Table 1. Effect of different proteases on activation of chitin synthase

\begin{tabular}{|c|c|c|c|}
\hline \multirow[t]{2}{*}{ Protease } & \multirow{2}{*}{$\begin{array}{c}\text { Concn } \\
\left(\mu \mathrm{g} \mathrm{ml}^{-1}\right)\end{array}$} & \multicolumn{2}{|c|}{ Chitin synthase } \\
\hline & & $\begin{array}{l}\text { Activity } \\
\left(\mathrm{U} \mathrm{ml}^{-1}\right)\end{array}$ & $\begin{array}{l}\text { Activation } \\
\text { ratio }\end{array}$ \\
\hline None & - & $8 \cdot 6$ & - \\
\hline \multirow[t]{3}{*}{ Acid protease } & 2 & $7 \cdot 9$ & 0.9 \\
\hline & 4 & $9 \cdot 6$ & $1 \cdot 1$ \\
\hline & 20 & $8 \cdot 8$ & $1 \cdot 0$ \\
\hline \multirow[t]{3}{*}{ Chymotrypsin } & 2 & $13 \cdot 6$ & $1 \cdot 6$ \\
\hline & 4 & $10 \cdot 4$ & $1 \cdot 2$ \\
\hline & 20 & $8 \cdot 2$ & 0.9 \\
\hline \multirow[t]{3}{*}{ Pronase } & 2 & $10 \cdot 1$ & $1 \cdot 2$ \\
\hline & 4 & $11 \cdot 5$ & $1 \cdot 3$ \\
\hline & 20 & $18 \cdot 4$ & $2 \cdot 1$ \\
\hline \multirow[t]{3}{*}{ Trypsin } & 2 & $29 \cdot 3$ & $3 \cdot 4$ \\
\hline & 4 & $26 \cdot 8$ & $3 \cdot 1$ \\
\hline & 20 & $13 \cdot 6$ & $1 \cdot 6$ \\
\hline
\end{tabular}

tonin, the total activity in the peak of chitin synthase was only $7 \cdot 1 \%$ of that measured in the presence of digitonin.

\section{Activation of digitonin-soluble chitin synthase with the different proteases}

Four different proteases were tested for their ability to activate the chitin synthase zymogen (Table 1). Acid protease failed to activate chitin synthase. Chymotrypsin and pronase produced stimulations up to twofold.

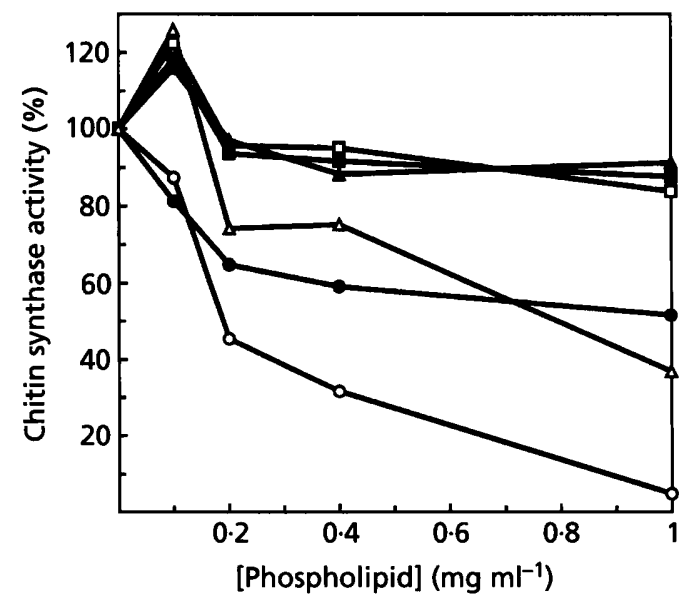

Fig. 3. Effect of phospholipids on digitonin-soluble chitin synthase. Crude digitonin-soluble chitin synthase (extracted with $10 \mathrm{mg}$ digitonin $\mathrm{ml}^{-1}$ ) was assayed in the presence of different amounts of phospholipids. Each phospholipid was

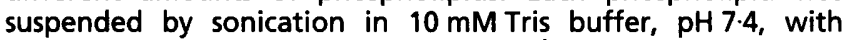
$0.5 \mathrm{M}$ sorbitol, and $10 \mathrm{mg}$ digitonin $\mathrm{ml}^{-1}$ and added $(50 \mu \mathrm{l})$ to the assay (final vol. $200 \mu \mathrm{l}$ ). 0 , Lysophosphatidylcholine; $\square$, phosphatidylcholine; $\boldsymbol{\Delta}$, phosphatidylethanolamine; $O$, phosphatidylglycerol; $\square$, phosphatidylinositol; $\triangle$, phosphatidylserine; Chitin synthase activity in the control was $7.4 \mathrm{U} \mathrm{ml} \mathrm{m}^{-1}$.

Trypsin gave the highest activation ( $3 \cdot 4$-fold) and was therefore used routinely in all assays at $2 \mu \mathrm{g} \mathrm{ml}^{-1}$.

\section{Effect of phospholipids}

Six phospholipids were tested for their effect on digitonin-soluble chitin synthase. Four of them, phosphatidylinositol, phosphatidylcholine, phosphatidylethanolamine and phosphatidylserine, produced a slight stimulation at the lowest concentration tested (Fig. 3). Additional tests, not shown, done at lower concentrations did not show any higher stimulations. Phosphatidylglycerol and lysophosphatidylcholine were not stimulatory at all. These two phospholipids and also phosphatidylserine became strongly inhibitory at concentrations $>0 \cdot 1 \mathrm{mg} \mathrm{ml}^{-1}$.

\section{Optimum pH}

The effect of $\mathrm{pH}$ on digitonin-soluble chitin synthase activity was measured in Tris/maleate ( $\mathrm{pH} 5.0-9.5$ ) or Tris/ $\mathrm{HCl}(\mathrm{pH} 7 \cdot 5-9 \cdot 0)$ buffers. In either buffer, gradientpurified soluble chitin synthase showed high activity above $\mathrm{pH} 6.8$ with a maximum at $7 \cdot 2-7 \cdot 6$.

\section{Stability of digitonin-soluble chitin synthase}

In general, samples of crude digitonin-soluble chitin synthase (before or after purification by density-gradient centrifugation) were relatively stable. Thus a gradientpurified sample stored at $4{ }^{\circ} \mathrm{C}$ lost only $15 \%$ activity after $48 \mathrm{~h}$ and $25 \%$ after $96 \mathrm{~h}$. 


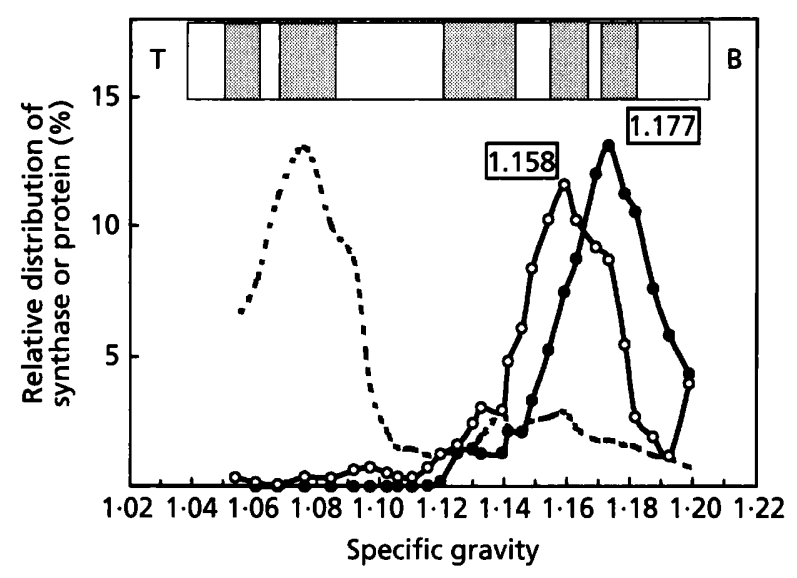

Fig. 4. Isopyenic separation of subcellular fractions with chitin synthase activity. A $3 \mathrm{ml}$ sample of crude cell homogenate was loaded on a $32 \mathrm{ml}$ sucrose gradient $(15-54 \%, w / v)$ and centrifuged for $20 \mathrm{~h}$ at $75100 \mathrm{~g}\left(R_{\mathrm{av}}\right)$. Fractions of $1.5 \mathrm{ml}$ were collected and assayed for chitin synthase activity (O), 1,3- $\beta$ glucan synthase activity $(O)$ and protein content (-- ). The relative distribution of each component was calculated as a percentage of the total recovered in the gradient. Values in boxes show the specific gravity of peak samples. The corresponding position of the turbidity bands in the gradient is shown at the top (T, top; B, bottom).

\section{Comparison of chitin synthase yields in two cultivation media}

Of the two different cultivation media used (Machlis and Machlis plus), Machlis plus yielded $2 \cdot 8$ times more mycelium and 1.4 times more total chitin synthase units but the specific activity was $40 \%$ lower. There was no difference in chitin synthase stability in either medium. We chose Machlis plus for isolation purposes because the total amount of enzyme collected was higher.

\section{Separation of subcellular fractions with chitin and glucan synthase activity}

A $3 \mathrm{ml}$ sample of crude cell homogenate was separated on a sucrose gradient and centrifuged at $75100 \mathrm{~g}\left(R_{\mathrm{av}}\right)$ in a swinging-bucket rotor. Fractions of $1.5 \mathrm{ml}$ were collected and assayed for chitin synthase and glucan synthase activity. Fig. 4 shows a representative result from eight separate experiments. The two bands containing these enzyme activities separated cleanly from the other turbidity bands and equilibrated near the bottom of the gradient. The 1,3- $\beta$-glucan synthase stabilized at an average peak density of $1 \cdot 158$. The peak density for chitin synthase was $1 \cdot 177$. The peak of chitin synthase was sharp; the 1,3- $\beta$-glucan synthase showed a shoulder that coincided with the peak of chitin synthase.

\section{Search for a chitosome fraction}

A procedure used for chitosome separation in other fungi, based on velocity sedimentation (Leal-Morales $e t$ al., 1988, 1994), was tested. Two cell homogenates were compared: (1) mycelium broken in the Virtis hom-

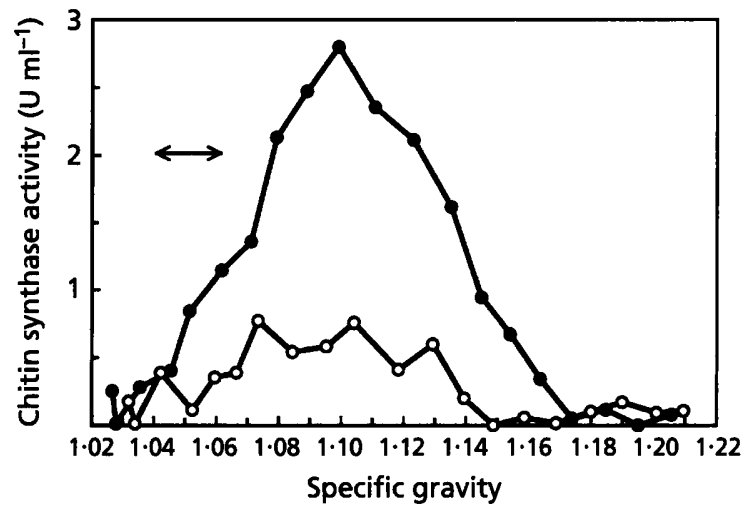

Fig. 5. Velocity sedimentation of subcellular fractions with chitin synthase activity. Samples of crude cell homogenates from mycelium broken by two different procedures, homogenization with a Virtis blender $(O)$ or ballistic disruption with a Braun homogenizer (O), were applied to linear sucrose density gradients $(10-60 \%, w / v)$, and centrifuged at $75100 \mathrm{~g}$ $\left(R_{\mathrm{av}}\right)$ for $1 \mathrm{~h}$ in the SW-27 rotor. The gradients were fractionated in $0.9 \mathrm{ml}$ fractions and chitin synthase determined in every other fraction. The double-headed arrow shows the zone where a chitosome peak would be expected.

ogenizer, as done in all other work reported here and before (Gay et al., 1993); and (2) mycelium disrupted in a Braun homogenizer. The cell homogenates were separated by a short centrifugation ( $1 \mathrm{~h})$ on linear $10-60 \%$ sucrose density gradients (Fig. 5). With both samples, the chitin synthase activity spread over a wide zone. The sample broken in the Virtis homogenizer yielded a broad jagged peak of chitin synthase. A single broad peak with much higher yields of chitin synthase was obtained in the sample disrupted in the Braun homogenizer. In neither sample was there clear evidence of a slow-moving population of chitin-synthase particles (chitosomes). Such a population would be expected to run in the upper part of the gradient (below $1.06 \mathrm{~g} \mathrm{~m}^{-1}$ ) under the centrifugation conditions tested.

\section{Determination of sedimentation coefficient}

From the relative sedimentation velocity on an isokinetic sucrose density gradient (see Methods) we estimated that the digitonin-soluble chitin synthase of $S$. monoica had a sedimentation coefficient of $13 \cdot 2 \mathrm{~S}$.

\section{Purification of digitonin-soluble chitin synthase by density-gradient centrifugation}

As an initial step in the purification of digitonin-soluble chitin synthase a density-gradient centrifugation step was introduced. Media of two different densities were compared: sucrose and glycerol. A mixed membrane fraction was extracted with $50 \mathrm{mg}$ digitonin $\mathrm{ml}^{-1}$; the sample $(9 \mathrm{ml})$ was divided in two: one half was applied to a glycerol gradient $(20-75 \%, \mathrm{v} / \mathrm{v})$, the other to a sucrose gradient $(10-65 \%, \mathrm{w} / \mathrm{v})$. Both were centrifuged for $3.75 \mathrm{~h}$ at $265000 \mathrm{~g}$ in a $70 \mathrm{Ti}$ rotor. Two peaks were 


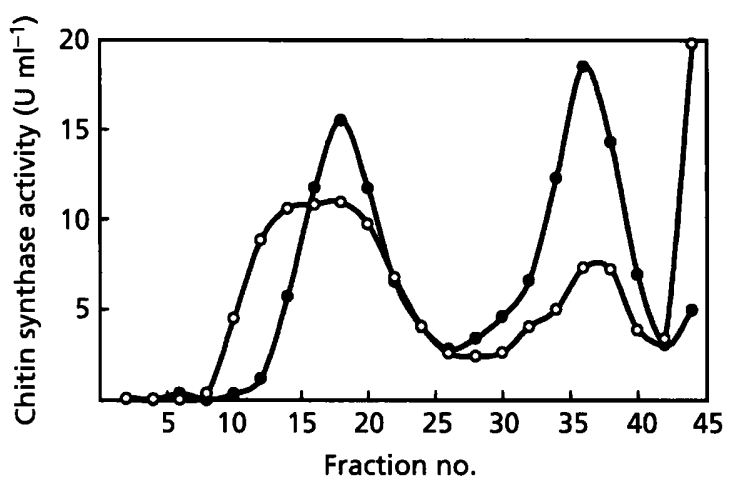

Fig. 6. Purification of digitonin-soluble chitin synthase by density-gradient centrifugation. Comparison between glycerol and sucrose linear density gradients. Samples of crude

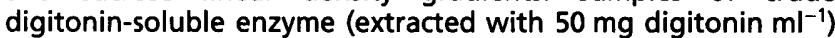
were applied on top of either a linear glycerol gradient $(20-75 \%, v / v)(O)$ or a linear sucrose gradient $(10-60 \%, w / v)$ (O). The gradients were centrifuged at $265000 \mathrm{~g}\left(R_{\mathrm{av}}\right)$ for $3.75 \mathrm{~h}$ in a 70Ti rotor. Fractions of $0.9 \mathrm{ml}$ were collected and chitin synthase determined in every other fraction.

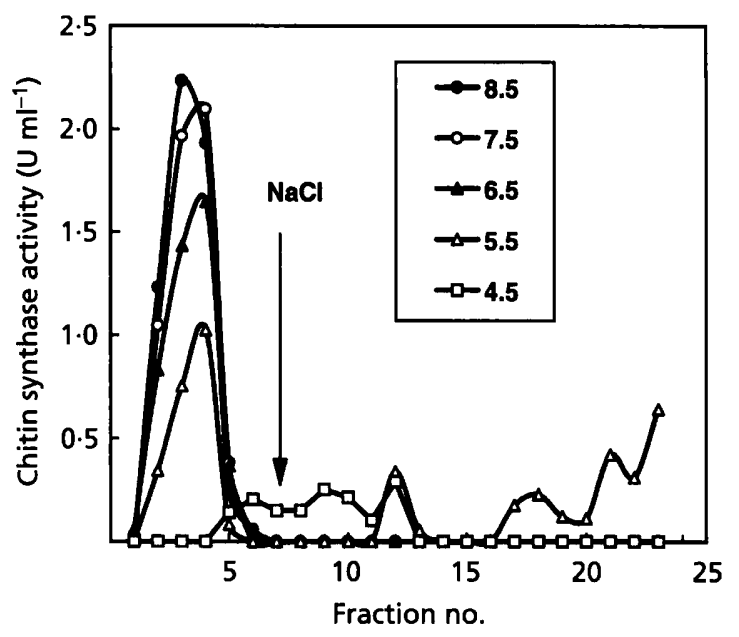

Fig. 7. Separation of digitonin-soluble chitin synthase by cation-exchange chromatography. Samples $(3 \mathrm{ml})$ of gradientpurified digitonin-soluble chitin synthase were applied to $20 \mathrm{HS}$ cation exchange columns equilibrated at the $\mathrm{pH}$ values shown in the inset. After loading the sample, the columns were eluted with $0-1 \mathrm{M} \mathrm{NaCl}$ gradients applied over a $5 \mathrm{~min}$ period at a rate of $2 \mathrm{ml} \mathrm{min}^{-1}$. Fractions of $2 \mathrm{ml}$ were collected and chitin synthase activity determined in all fractions.

cleanly resolved (Fig. 6): a slow-moving peak of digitonin-soluble enzyme and a fast-moving peak of incompletely solubilized enzyme. The latter plus the pellet accounted for around $60 \%$ of the activity applied to the gradient. The peak of solubilized chitin synthase was much sharper in the sucrose gradient and had a higher specific activity. Therefore sucrose gradients were used routinely in the purification of digitonin-soluble chitin synthase.

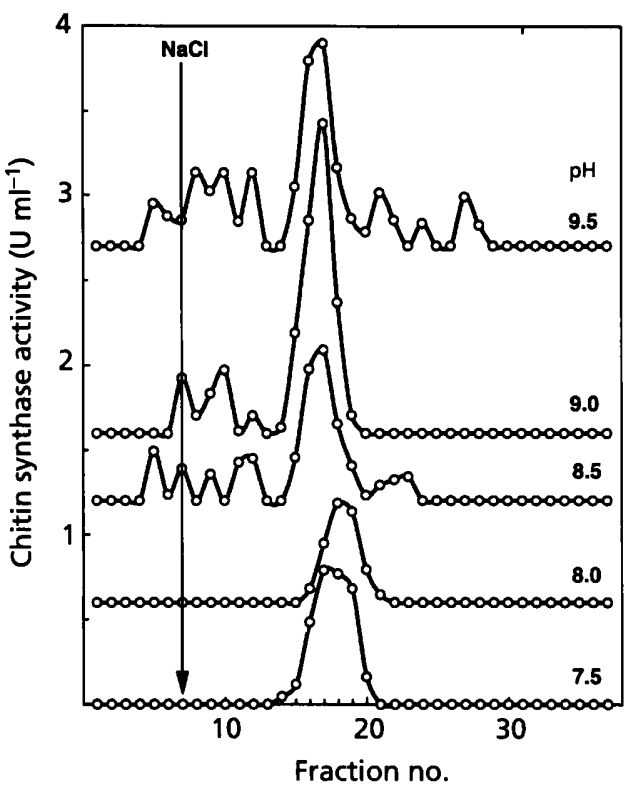

Fig. 8. Separation of digitonin-soluble chitin synthase by strong anion-exchange chromatography. Samples $(3 \mathrm{ml})$ of gradientpurified digitonin-soluble chitin synthase were applied to $20 \mathrm{HQ}$ strong anion-exchange columns equilibrated at the different $\mathrm{pH}$ values shown on the right of the figure. After loading the sample, the columns were eluted with gradients of $0-0.5 \mathrm{M}$ $\mathrm{NaCl}$ applied over a $25 \mathrm{~min}$ period at a rate of $5 \mathrm{ml} \mathrm{min}-1$. Fractions of $2 \mathrm{ml}$ were collected and chitin synthase activity determined in all fractions.

\section{Purification of digitonin-soluble chitin synthase by ion-exchange chromatography}

Based on prior experience (Lending et al., 1991), we fully explored the separation of soluble chitin synthase from S. monoica on a $20 \mathrm{HS}$ cation-exchange column, a strong cation exchanger, but the enzyme did not bind to the column at any of the wide range of $\mathrm{pHs}$ tested, from 4.5 to 8.5 (Fig. 7). Up to $90 \%$ of the activity applied was recovered in the unbound fraction. As measured by UV absorbance, a considerable percentage of the protein in the sample did bind to the column $(34 \%$ at $\mathrm{pH} 4.5$ and $12 \%$ at $\mathrm{pH} 7 \cdot 5$ ).

We tested the separation of gradient-purified digitoninsoluble chitin synthase on both strong (20HQ column) and weak (20PI column) anion-exchangers. The 20HQ columns were equilibrated and eluted with buffers in the $\mathrm{pH}$ range $4 \cdot 5-9 \cdot 5$. At $\mathrm{pH} 4 \cdot 5$, all activity was lost and none was recovered in either the non-bound or eluted fractions. At all other $\mathrm{pH}$ values, chitin synthase eluted as a single peak and the best yield was obtained at $\mathrm{pH} 8$ 8.5. Further tests done in the $\mathrm{pH}$ range 7.5-9.5 (Fig. 8) showed that elution at $\mathrm{pH} 9$ yielded the highest recovery $(52 \%)$ together with the highest chitin synthase specific activity $(11 \cdot 8)$ relative to UV absorbance.

The 20PI columns were equilibrated and eluted with buffers in the $\mathrm{pH}$ range of $6.5-9.5$, in increments of 1.0 unit. In all, chitin synthase eluted as a single peak, and 


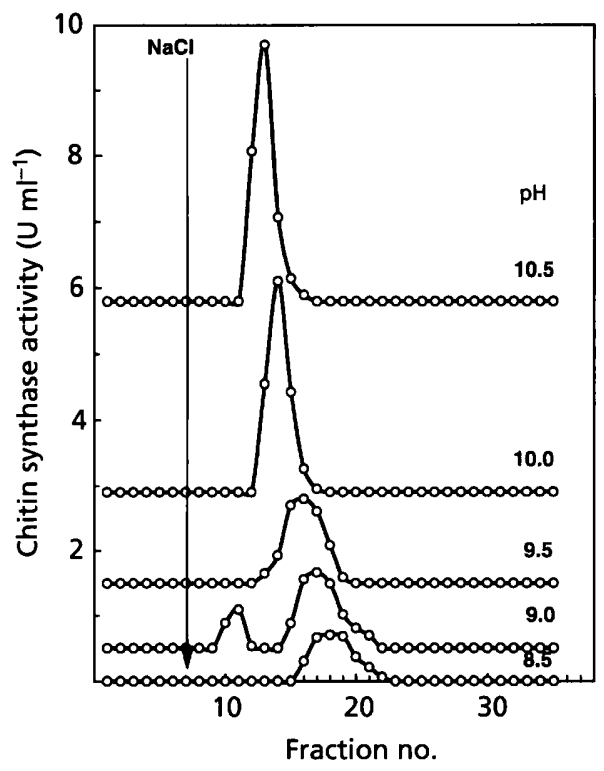

Fig. 9. Separation of digitonin-soluble chitin synthase by weak anion-exchange chromatography. Samples $(3 \mathrm{ml})$ of gradientpurified digitonin-soluble chitin synthase were applied to 20PI weak anion-exchange columns equilibrated at the $\mathrm{pH}$ values shown on the right of the figure. The columns were eluted with gradients of $0-1 \mathrm{M} \mathrm{NaCl}$ applied over a $10 \mathrm{~min}$ period at a rate of $5 \mathrm{ml} \mathrm{min}^{-1}$. Fractions of $2 \mathrm{ml}$ were collected and chitin synthase activity determined in all fractions.

the best yield was observed at $\mathrm{pH} 9 \cdot 5$. Further tests done in the $\mathrm{pH}$ range $8.5-10.5$ (Fig. 9) revealed that the highest chitin synthase recoveries $(72-77 \%)$ and highest specific activities $(13 \cdot 8-13 \cdot 2)$ were at $\mathrm{pH} 10$ and $10 \cdot 5$.

\section{Purification of digitonin-soluble chitin synthase by consecutive chromatography on strong and weak anion exchangers}

A large sample of soluble chitin synthase was processed by combining digitonin-soluble enzyme from four sucrose density gradients $(41 \mathrm{ml})$. The sample was applied to two 20HQ columns (connected in tandem) and eluted with $\mathrm{NaCl}$ buffered at $\mathrm{pH} 9$ (Fig. 10a). About $37 \%$ of the chitin synthase activity applied was recovered. Most of the bound chitin synthase was eluted in a single rather broad peak. Only a small portion of the chitin synthase failed to bind to the column but over half of the protein (based on $A_{280}$ ) in the sample did not bind to the column. The bound protein eluted as two peaks: the major one co-eluted with the single peak of chitin synthase activity. The seven most active chitin synthase fractions $(13 \mathrm{ml})$ from the strong anion-exchange separation were pooled, diluted to $104 \mathrm{ml}$, and applied to a double (tandem) 20PI column. All chitin synthase as well as all UV-absorbing material bound to the column. The column was eluted with a $\mathrm{NaCl}$ gradient buffered at $\mathrm{pH} 10 \cdot 0$ (Fig. 10b). There was good recovery of chitin synthase activity $(40 \%)$ mostly as a single peak. The eluted proteins
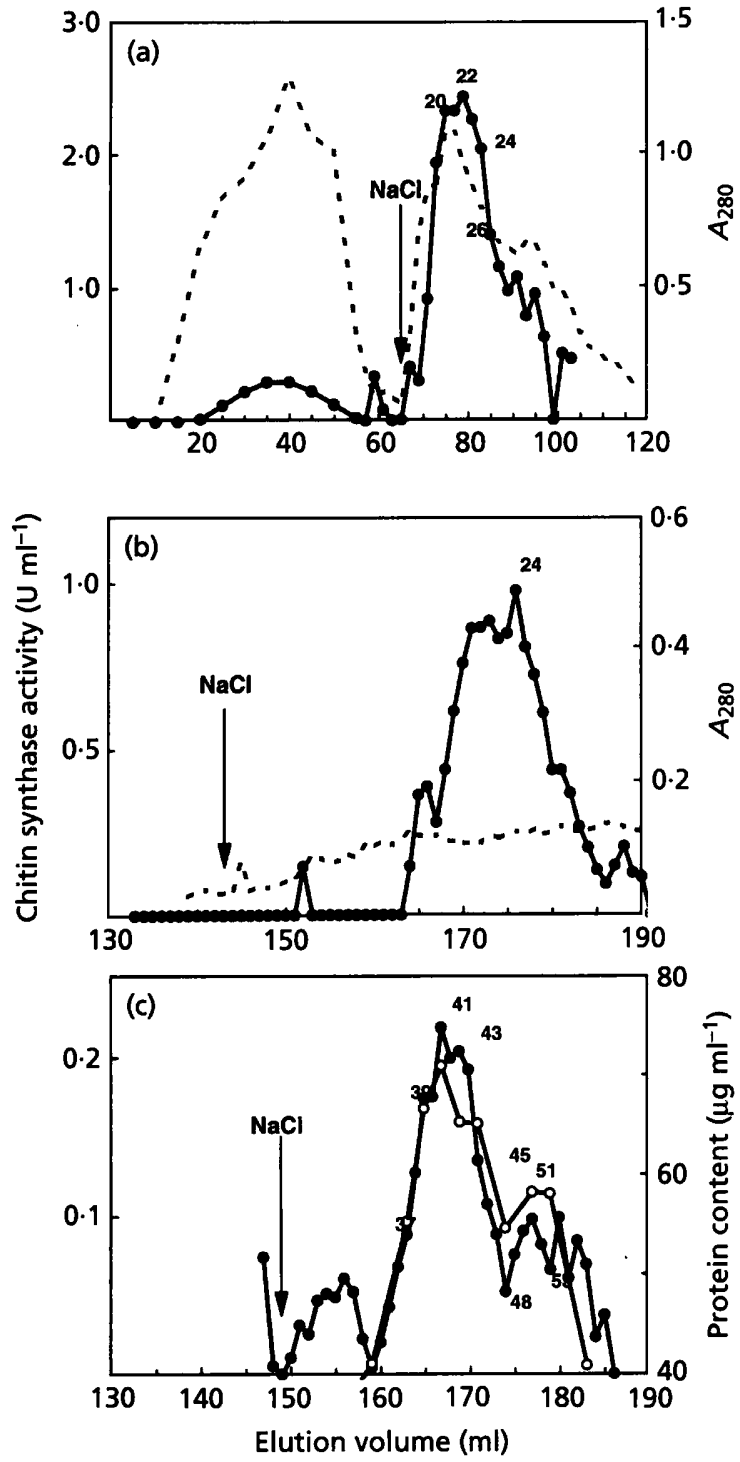

Fig. 10. Purification of digitonin-soluble chitin synthase by consecutive ion-exchange chromatography. (a) Strong anion exchanger. Fractions of purified digitonin-soluble chitin synthase from four sucrose gradients were pooled (total vol. $41 \mathrm{ml}$ ) and applied at a flow rate of $2 \mathrm{ml} \mathrm{min}^{-1}$ to a double strong anion exchanger column (two 20HQ columns in tandem) equilibrated at $\mathrm{pH} 9 \cdot 0$. A $0-1 \mathrm{M} \mathrm{NaCl}$ elution gradient was applied over a $25 \mathrm{~min}$ period at a flow rate of $2 \mathrm{ml} \mathrm{min}^{-1}$. (b) Weak anion exchanger. The seven most active chitin synthase fractions from (a) were pooled, diluted to $104 \mathrm{ml}$ (unbuffered $20 \%$ glycerol containing $0.1 \%$ digitonin), applied to a double PI column and eluted at pH 10.0 at a flow rate of $4 \mathrm{ml} \mathrm{min}^{-1}$ with a $0-0.25 \mathrm{M} \mathrm{NaCl}$ gradient in $25 \mathrm{~min}$. Fractions $(2 \mathrm{ml}$ each) were collected and placed on ice. Chitin synthase activity (O) and $A_{280}(--)$ were determined. (c) Re-chromatography on a weak anion exchanger. The entire chitin synthase peak from (b) was pooled, diluted fourfold (unbuffered $20 \%$ glycerol containing $0.1 \%$ digitonin) and reapplied to a double 20PI column. The elution was performed as in (b). Chitin synthase activity $(O)$ and protein content $(O)$ were determined.

(based on $A_{280}$ ) extended over the entire salt gradient, but the main peak of chitin synthase was sharp. This entire chitin synthase peak was pooled, diluted fourfold 


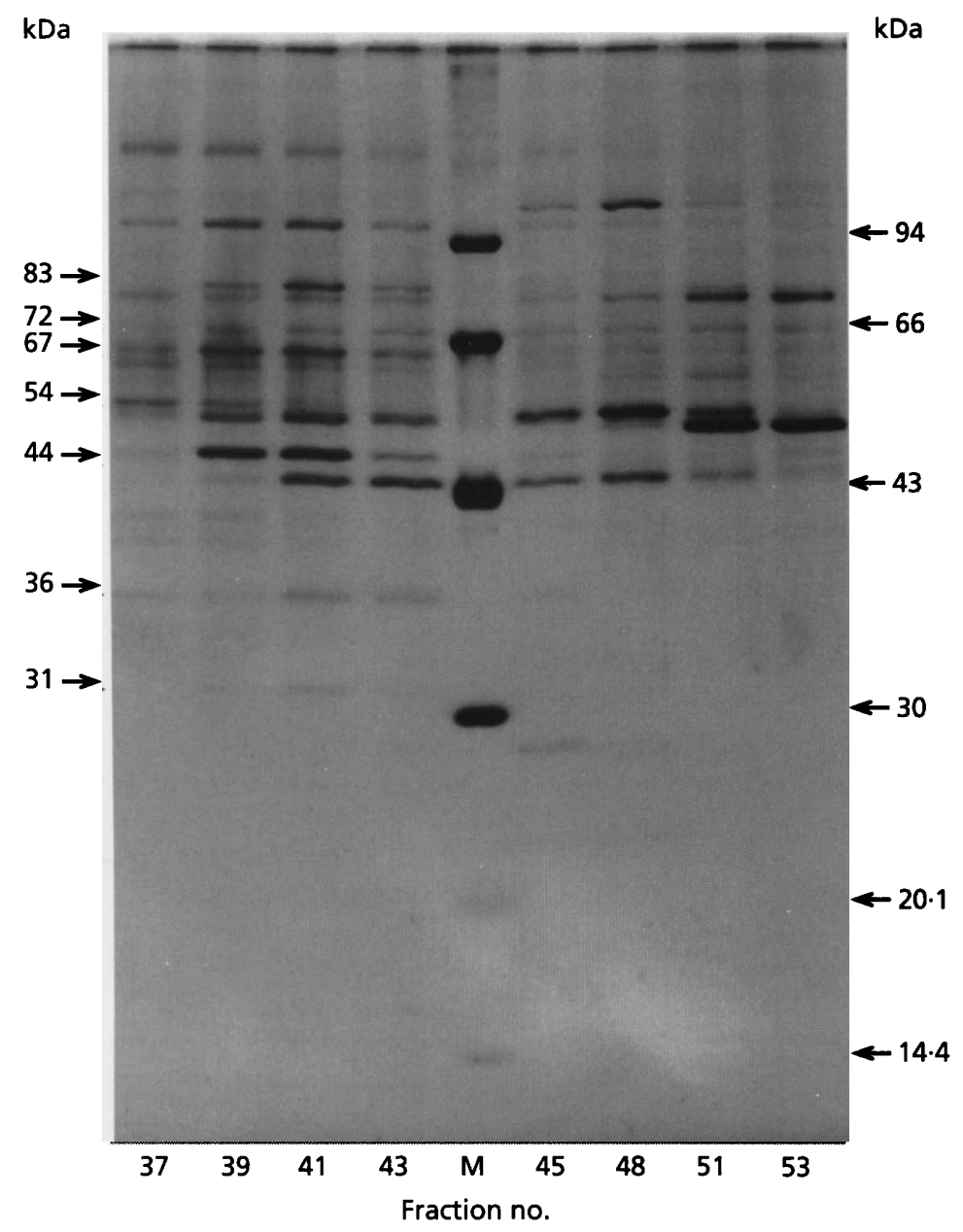

Fig. 11. SDS-PAGE analysis of purified chitin synthase. Selected fractions from the main peak of chitin synthase (Fig. 10c) were electrophoresed on a $10-15 \%$ polyacrylamide gel and silver stained. Arrows on the left show bands that co-chromatographed with the peak of chitin synthase. Molecular mass markers (lane $M$ ) are shown on the right.

and applied to another double 20PI column. The resulting chitin synthase peak co-chromatographed with the main protein peak measured by Bradford assays (Fig. 10c).

\section{Electrophoretic analysis}

Eight fractions constituting the peak of purified chitin synthase (see Fig. 10c) were analysed by SDS-PAGE. The amount of protein present in this purified sample was exceedingly small $(2 \cdot 4 \mu \mathrm{g}$ applied) but the high sensitivity of silver staining allowed us to detect 19 bands, from 27 to $125 \mathrm{kDa}$, in the fractions with chitin synthase activity. Five of them showed intensities that paralleled the chitin synthase activity in the fractions, namely $83,72,67,36$ and $31 \mathrm{kDa}$ (Fig. 11). Two other bands, at 54 and $44 \mathrm{kDa}$, paralleled the chitin synthase peak but they also showed a second intensity peak in fraction no. 48 where there was no chitin synthase activity - an indication that another protein of similar molecular mass was also present in the bands. Of all these seven bands, the one at $72 \mathrm{kDa}$ had a profile that more closely paralleled the main peak of chitin synthase, and also showed correspondence with the minor peak of chitin synthase in fraction 51 (Fig. 10c).

\section{DISCUSSION}

Throughout the fungi, major cell wall components have been largely conserved. The vast majority of the fungi (mainly the mycelial Ascomycetes and Basidiomycetes) have chitinous cell walls made of chitin microfibrils embedded in an abundance of 1,3- $\beta$-glucan(s) (BartnickiGarcía, 1968, 1987a). In the Oomycetes, the characteristic cellulosic fungi, microfibrils of cellulose are embedded in a matrix of $1,3-\beta$-glucans. The mere presence of either cellulose or chitin cannot be considered a group-defining characteristic since small amounts of chitin can occur in some species of the Oomycetes; conversely cellulose is found occasionally in higher fungi (Rosinski \& Campana, 1964). The presence of chitin in a typical cellulosic fungus like $S$. monoica poses intriguing questions as to its role, subcellular localization and evolutionary significance. It is not clear what role chitin plays in the wall properties of this cellulosic fungus. As shown by electron microscopy and electron diffraction (Gay et al., 1992; Bulone et al., 1992), the $\alpha$-chitin found in hyphal walls of $S$. monoica is non-fibrillar. Staining with fluorescent wheatgerm agglutinin failed to reveal any particular pattern of chitin distribution; this polysaccharide is deposited uniformly throughout the mycelial walls of $S$. 
monoica (unpublished results). The fact that inhibition of chitin synthesis by polyoxin does not affect growth significantly (Bulone et al., 1992) suggests that the chitin does not play a vital role in this fungus.

In addition to differences in subcellular localization, the solubilized chitin synthase of $S$. monoica shows properties that distinguish it from chitin synthases from other fungi.

Previous studies on the chitin synthase of $S$. monoica (Bulone et al., 1992; Gay et al., 1993) stressed the points of similarity between the chitin synthase of $S$. monoica and other fungi, namely zymogenicity, metal requirement, inhibition by polyoxin, solubilization by digitonin. The present study shows that the enzyme differs markedly in several features

1. A major difference is in cellular localization. Whereas in typical fungi, chitin synthase can be found in two subcellular sites, chitosomes and plasma membrane (Leal-Morales et al., 1988; Bartnicki-García \& Bracker, 1984; Leal-Morales et al., 1994), we found no evidence that the enzyme of $S$. monoica is present in chitosomes; the observed activity was all in a presumptive plasma membrane fraction. Chitosomes are considered to be the key components of a unique secretory pathway for the delivery of chitin synthase to the cell surface (LealMorales et al., 1994), a view recently reinforced by immunocytochemical labelling of Neurospora crassa microvesicles with an anti-chitin synthase (CHS2 gene product) antibody (Sietsma et al., 1996). In S. monoica, however, we found no evidence that chitin synthase was associated with a population of small vesicles of low density $(1 \cdot 12-1 \cdot 15)$, the typical indicators of chitosomes. Similarly, a milder centrifugation did not disclose a separate slow-moving population of vesicles with chitin synthase activity. Our results do not rule out entirely the presence of chitosomes in this organism, but if present they may have exceptional qualities, not evident in chitosomes from other fungi, for example being too fragile or unstable to survive any breakage procedure, or having a drastically different buoyant density. Perhaps the fact that chitin is not an essential component in $S$. monoica obviates the need for a chitosome secretory pathway. Equilibrium density centrifugation showed that chitin synthase sediments with membranous components of the highest specific gravity (1.177) in the cell homogenate of $S$. monoica. Whether this is a plasma membrane fraction remains to be determined. The main portion of the 1,3- $\beta$-glucan synthase, an enzyme activity associated with the plasma membrane (Fèvre et al., 1989), sedimented in a peak with much lower density $(1 \cdot 158)$ and was clearly distinguished from the chitin synthase peak. There was, however, a minor portion of the 1,3- $\beta$-glucan synthase (a shoulder on the main peak) that co-sedimented with chitin synthase.

2. As in other fungi the chitin synthase from S. monoica was dissociated by digitonin, and the solubilized chitin synthase remained zymogenic, but its sedimentation coefficient of $13 \cdot 2 \mathrm{~S}$ is significantly lower than the $16 \mathrm{~S}$ value for the solubilized enzyme from $M$. rouxii (Ruiz-
Herrera et al., 1980) or Agaricus bisporus (Hanseler et al., 1983), or the value of $18.4 \mathrm{~S}$ for Saccharomyces cerevisiae (Kang et al., 1984).

3. The enzyme from $S$. monoica was not stimulated much by any of several phospholipids tested, contrary to the behaviour of chitin synthases from Saccharomyces cerevisiae (Duran \& Cabib, 1978); Schizophyllum commune (Vermeulen \& Wessels, 1983); Candida albicans (Braun \& Calderone, 1979); M. rouxii (Lending et al., 1991); Coprinus cinereus (Montgomery \& Gooday, 1985) or Fusarium graminearum (Binks et al., 1990).

4. The chitin synthase of $S$. monoica is unique in its degree of response to digitonin. In other chitin synthases, for example $M$. rouxii (Ruiz-Herrera et al., 1980), A. bisporus (Hanseler et al., 1983) or C. albicans (Gozalbo et al., 1993), the stimulation by digitonin was never greater than 2-3-fold (vs the 26-fold increase in $S$. monoica) and there was considerable or total inhibition at higher concentration of the saponin. Two explanations for the exceedingly low chitin synthase activity of $S$. monoica in the absence of digitonin are: (1) the UDPGlcNAc substrate is not able to reach the enzyme in the membrane fractions unless the membrane barrier is disrupted by the saponin; or (2) chitin synthase preparations from S. monoica lack an endogenous acceptor but can use digitonin to initiate chitin synthesis. The first explanation is unlikely since the stimulatory effect was also manifested by dissociated chitin synthase purified through a sucrose density gradient. The near absolute requirement for digitonin suggests that this sterol glycoside may function as an artificial acceptor. The possibility that digitonin serves as an acceptor for chitin synthase to initiate chain synthesis brings up the question of what molecule functions as the natural acceptor of chitin synthase in vivo.

5. Unlike the enzyme from $M$. rouxii, the solubilized chitin synthase from $S$. monoica did not bind to cation exchangers. This is a good indication of substantial difference in the amino acid composition of the $S$. monoica chitin synthase.

The fact that the chitin synthase from S. monoica has such unique properties is not surprising given the phylogenetic distance between the Oomycetes and other major classes of fungi. Note that according to BartnickiGarcía (1996) biochemical/molecular idiosyncrasies, such as those reported here, should not outweigh other more general reasons for keeping the Oomycetes together with the rest of the fungi in a single diphyletic kingdom (Fungi).

The digitonin-solubilized chitin synthase of S. monoica was purified by a four-step procedure that included sucrose density-gradient centrifugation, a single passage through a strong anion exchanger and two consecutive passages through a weak anion exchanger. After this extensive purification, the final peak of chitin synthase yielded, upon dissociation with SDS and gel electrophoresis, a number of polypeptide bands, seven of which $(31,36,44,54,67,72$ and $83 \mathrm{kDa})$ co-chromatographed with the chitin synthase activity. Since enzyme activity 
was irreversibly lost upon dissociation with SDS, we could not ascertain which of the above polypeptide bands contained the catalytic domain of chitin synthase. Since there was no electrophoretic evidence for a single polypeptide of large molecular mass (around $400 \mathrm{kDa}$ ) that would account for the high sedimentation coefficient of the purified digitonin-solubilized chitin synthase, we conclude that the digitonin-dissociated particles are macromolecular complexes made from combinations of the above polypeptides. The observed multiplicity of polypeptide bands in the purified sample suggests that it contained contaminating macromolecular complexes of similar size and charge. Therefore, it is not possible to state unequivocally which of the detected polypeptides belong to the chitin synthase complex. A similar study of chitin synthase from $M$. rouxii solubilized with digitonin (16 $\mathrm{S}$ particles) revealed several polypeptide bands in the final step of purification, four of which $(21,23,33$ and $39 \mathrm{kDa})$ were proposed to be the components of a macromolecular complex that synthesizes chitin microfibrils (Lending et al., 1991). That S. monoica and M. rouxii yielded a different mix of polypeptides is not surprising given the different size of the solubilized enzyme from S. monoica, its lack of a net cationic charge, and the sharp biochemical differences between Oomycetes and Zygomycetes (Bartnicki-García, 1970). Notwithstanding this discrepancy both studies suggest that macromolecular complexes are responsible for the synthesis of a chitin chain in a fungal cell. Dissociation of these complexes with strong detergents results in a seemingly irreversible loss of activity.

\section{ACKNOWLEDGEMENTS}

This research was supported in part by grants from the National Institutes of Health (GM-48257) and the National Science Foundation (IBN-9204541) and the Centre National de la Recherche Scientifique (UMR-5534).

\section{REFERENCES}

Aronson, J. M. \& Lin, C. C. (1978). Hyphal wall chemistry of Leptomitus lacteus. Mycologia 70, 363-369.

Bartnicki-García, S. (1968). Cell wall chemistry, morphogenesis, and taxonomy of fungi. Annu Rev Microbiol 22, 87-108.

Bartnicki-Garcfa, S. (1970). Cell wall composition and other biochemical markers in fungal phylogeny. In Phytochemical Phylogeny, pp. 81-103. Edited by J. B. Harborne. London: Academic Press.

Bartnicki-Garcla, S. (1987). The cell wall: a crucial structure in fungal evolution. In Evolutionary Biology of the Fungi, pp. 389-403. Edited by A. D. M. Rayner, C. M. Brasier \& D. Moore. Cambridge: Cambridge University Press.

Bartnicki-Garcla, S. (1996). The hypha: unifying thread of the fungal kingdom. In A Century of Mycology, pp. 105-133. Edited by B. Sutton. Cambridge: Cambridge University Press.

Bartnicki-Garcla, S. \& Bracker, C. E. (1984). Unique properties of chitosomes. In Microbial Cell Wall Synthesis and Autolysis, pp. 101-112. Edited by C. Nombela. Amsterdam: Elsevier.

Binks, P. R., Robson, G. D., Goosey, M. W., Humphreys, A. \& Trinci, A. P. J. (1990). Chitin synthesis in Fusarium graminearum and its inhibition by edifenphos (Hinosan). J Gen Microbiol 137, 615-620.

Braun, P. C. \& Calderone, R. A. (1979). Regulation and solubilization of Candida albicans chitin synthetase. J Bacteriol 140, 666-670.

Bulawa, C. E. (1993). Genetics and molecular biology of chitin synthesis in fungi. Annu Rev Microbiol 47, 505-534.

Bulone, V., Chanzy, H., Gay, L., Girard, V. \& Fèvre, M. (1992). Characterization of chitin and chitin synthase from the cellulosic cell wall fungus Saprolegnia monoica. Exp Mycol 16, 8-21.

Campos-Takaki, G. B., Dietrich, S. M. \& Mascarenhas, Y. (1982). Isolation and characterization of chitin from cell walls of Achlya radiosa. J Gen Microbiol 128, 207-209.

Cline, K., Andrews, J., Mersey, B., Newcomb, E. H. \& Keegstra, K. (1981). Separation and characterization of inner and outer envelope membranes of pea chloroplast. Proc Natl Acad Sci USA 78, 3595-3599.

Duran, A. \& Cabib, E. (1978). Solubilization and partial purification of yeast chitin synthetase. J Biol Chem 253, 4419-4425.

Fèvre, M., Girard, V. \& Nodet, P. (1989). Cellulose and $\beta$-glucan synthesis in Saprolegnia. In Biochemistry of Cell Walls and Membranes in Fungi, pp. 97-107. Edited by P. J. Kuhn, A. P. J. Trinci, M. J. Jung, M. W. Goosey \& L. G. Copping. Berlin: Springer.

Gay, L., Hébraud, M., Girard, V. \& Fèvre, M. (1989). Chitin synthase activity from Neocallimastix frontalis, an anaerobic rumen fungus. J Gen Microbiol 135, 279-286.

Gay, L., Bulone, V., Girard, V., Fèvre, M. \& Chanzy, H. (1992). Chitin pleomorphism in the cellulosic cell wall fungus Saprolegnia. FEMS Microbiol Lett 100, 405-409.

Gay, L., Chanzy, H., Bulone, V., Girard, V. \& Fèvre, M. (1993). Synthesis in vitro of crystalline chitin by a solubilized enzyme from the cellulosic fungus S. monoica. J Gen Microbiol 139, 2117-2122.

Gooday, G. W. (1990). Inhibition of chitin metabolism. In Biochemistry of Cell Walls and Membranes in Fungi, pp. 61-79. Edited by P. J. Kuhn, A. P. J. Trinci, M. J. Jung, M. W. Goosey \& L. G. Copping. Berlin: Springer.

Gozalbo, D., Dubón, F. \& Sentandreu, R. (1993). Effect of digitonin on membrane-bound and chitosomal chitin synthetase activity in protoplasts from yeast cells of Candida albicans. Antonie Leeuwenboek 64, 67-74.

Hanseler, E., Nyhlén, L. E. \& Rast, D. M. (1983). Isolation and properties of chitin synthetase from Agaricus bisporus mycelium. Exp Mycol 7, 17-30.

Huizar, H. E. \& Aronson, J. M. (1986). Aspects of cellulin deposition and chitin biosynthesis in the Leptomitaceae. Mycologia 78, 489-492.

Huizar, H. E. \& Aronson, J. M. (1987). Chitin synthase. In Zoosporic Fungi in Teaching and Research, pp. 214-218. Edited by M. S. Fuller \& A. Jaworski. Athens, GA: Southeastern.

Kang, M. S., Elango, N., Mattia, E., Au-Young, J., Robbins, P. W. \& Cabib, E. (1984). Isolation of chitin synthetase from Saccharomyces cerevisiae. Purification of an enzyme by entrapment in the reaction product. J Biol Chem 259, 14966-14972.

Leal-Morales, C. A., Bracker, C. E. \& Bartnicki-Garcia, S. (1988). Localization of chitin synthetase in cell-free homogenates of Saccharomyces cerevisiae: chitosomes and plasma membrane. Proc Natl Acad Sci USA 85, 8516-8520.

Leal-Morales, C. A., Bracker, C. E. \& Bartnicki-Garcia, S. (1994). Distribution of chitin synthetase and various membrane marker 
enzymes in chitosomes and other organelles of the slime mutant of Neurospora crassa. Exp Mycol 18, 168-179.

Lee, H. Y. \& Aronson, J. M. (1975). Composition of cellulin, the unique chitin-glucan granules of the fungus, Apodachlya sp. Arch Mikrobiol 102, 203-208.

Lending, C. R., Leal-Morales, C. A., Flores-Martinez, A., Bracker, C. E. \& Bartnicki-Garcla, S. (1991). Purification and characterization of $16 \mathrm{~S}$ chitin synthetase particles from cell walls of Mucor rouxii. Exp Mycol 15, 11-25.

Lin, C. C. \& Aronson, J. M. (1970). Chitin and cellulose in the cell walls of the Oomycete, Apodachlya sp. Arch Mikrobiol 72, 111-114.

Machlis, L. (1953). Growth and nutrition of water molds in the subgenus Euallomyces. II. Optimal composition of the minimal medium. Am J Bot 40, 449-460.

Montgomery, G. W. G. \& Gooday, G. W. (1985). Phospholipidenzyme interactions of chitin synthase of Coprinus cinereus. FEMS Microbiol Lett 27, 29-33.

Mort-Bontemps, M., Gay, L. \& Fèvre, M. (1997). CHS2, a chitin synthase gene from the oomycete Saprolegnia monoica. Microbiology 143, 2009-2020.
Rosinski, M. A. \& Campana, R. J. (1964). Chemical analysis of the cell wall of Ceratocystis ulmi. Mycologia 56, 738-744.

Ruiz-Herrera, J., Bartnicki-Garcla, S. \& Bracker, C. E. (1980). Dissociation of chitosomes by digitonin into $16 \mathrm{~S}$ subunits with chitin synthetase activity. Biochim Biophys Acta 629, 201-216.

Ruiz-Herrera, J., Bracker, C. E. \& Bartnicki-García, S. (1984). Sedimentation properties of chitosomes from Mucor rouxii. Protoplasma 122, 178-190.

Sietsma, J. H., Din, A. B., Ziv, V., Sjollema, K. A. \& Yarden, O. (1996). The localization of chitin synthase in membranous vesicles (chitosomes) in Neurospora crassa. Microbiology 142, 15911596.

Vermeulen, C. A. \& Wessels, J. G. H. (1983). Evidence for a phospholipid requirement of chitin synthase in Schizopbyllum commune. Curr Microbiol 8, 67-71.

Wray, W., Boulikas, T., Wray, V. P. \& Hancock, R. (1981). Silver staining of proteins in polyacrylamide gels. Anal Biochem 118, 197-203.

Received 10 September 1996; revised 6 March 1997; accepted 12 March 1997. 